\title{
Two-stage therapeutic utility of ectopically formed bone tissue in skeletal muscle induced by adeno-associated virus containing bone morphogenetic protein-4 gene
}

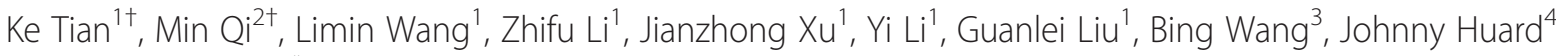
and Guangheng Li $i^{* *}$

\begin{abstract}
Background: The major disadvantage of using a stem cell-based bone morphogenetic protein-4 (BMP4) gene therapy for skull defect is the overgrowth of generated bone tissue in situ. In the present study, to overcome bony overgrowth of stem cell based-gene therapy, a new strategy of two-stage bone tissue engineering by an adeno-associated virus containing BMP4 gene (AAV-BMP4) gene therapy was used.

Methods: AAV-BMP4 was purposely implanted in the skeletal muscle of mice to generate ectopic bone tissues during the first stage. Next, the newly formed ectopic bone tissues were harvested and then transplanted to repair the mouse skull defect during the second stage.

Results: The results showed that skeletal muscle implantation of AAV-BMP4 yielded a large amount of new bone tissues. The ectopic bone tissues can be harvested as a bone graft and can successfully repair the mouse skull defect without any bony overgrowth in situ.
\end{abstract}

Conclusion: The results indicate that the bone tissues purposely generated by AAV-BMP4 in the skeletal muscle may be a new alternative of bone grafting for clinical purposes.

Keyword: Gene therapy, Adeno-associated virus, BMP4, Bone, Skeletal muscle, Skull defect

\section{Background}

Patients with clinical situations, such as skull defect, chronic non-unions of fracture, or spinal fusion may require repeated autologous bone grafts. The disadvantages of using autologous bone grafts include limited availability, donor-site morbidity, and reduced osteogenicity. Wright et al. have repaired long-bone and cranial defects by utilizing muscle-derived stem cells (MDSCs) transfected with bone morphogenetic proteins (BMPs) [1-3]. However, this approach has its limitation because MDSCs normally generate inappropriate overgrowth of bone tissue in situ. Although Hannallah et al. reported that the inappropriate

\footnotetext{
* Correspondence: liguangheng@hotmail.com

${ }^{\dagger}$ Equal contributors

'Department of Orthopedic Surgery, First Affiliated Hospital of Zhengzhou University, Zhengzhou 450003, Henan, China

Full list of author information is available at the end of the article
}

overgrowth can be prevented by multiple gene therapies, such as the combination of BMP4 and Noggin (BMP4 antagonist), the transfected cells must be tightly regulated which make the procedure difficult to manage $[4,5]$. Besides, the stem cell-based gene therapy is lengthy considering the time required for stem cell isolation, in vitro transfection, and implantation of cells until ossification in the defect is observed [6-8].

It is known that ectopic bone tissues in the skeletal muscle can be induced by injecting adeno-associated viruses (AAV) containing the bone morphogenetic protein (BMP) gene [9, 10]. However, it remains uncertain whether the bone tissue generated by the AAV-BMP4 induction can be used as a bone graft. Therefore, in the present study, a new strategy was used to overcome the disadvantages of stem cell-based gene therapy for the skull defect repair. In this strategy, ectopic bone formation in the skeletal was 
accomplished by the implantation of AAV-BMP4 during the first stage, and then the bone tissues were harvested and tested for its grafting capacity for skull defect repair during the second stage. Results generated from the present study provide us with a better understanding about ectopically formed bone tissues triggered by AAV-BMP4 in the skeletal muscle, which may be a new strategy for treating clinical patients with a need for bone grafts.

\section{Methods}

\section{Construction and production of AAV-BMP4}

Human BMP4 gene was carried by self-complementary AAV vectors [11]. The viral vector stocks of serotypes 6 of AAV-D(+)-BMP-4 were produced and purified according to published protocols [11], and vector titers were approximately $5 \times 10^{12}$ viral particles per $\mathrm{ml}(\mathrm{vp} / \mathrm{ml})$.
Skeletal muscle implantation of AAV-BMP4 in SCID mice The animal protocol using severe combined immunedeficient (SCID) mice in the present study was approved by the Experimental Animal Review Board of Zhengzhou University. Twelve pieces of Gelfoam (Pfizer, Kalamazoo, Michigan, $3 \times 3 \mathrm{~mm}^{2}$ ) soaked with $15 \mu \mathrm{l}$ AAV-BMP4 $\left(5 \times 10^{12} \mathrm{vp} / \mathrm{ml}\right)$ were implanted into both legs of six SCID mice. These mice were assessed by micro-CT at weeks 2, 12, and 24 after implantation surgery (Fig. 1a).

\section{Harvesting and transplantation of bone tissues in vivo}

The mice with AAV-BMP4 implantation surgery were sacrificed and ectopically generated bone tissue in the skeletal muscle pocket was harvested at week 12 . At the same time, another set of twelve host mice with skull defects were surgically created [5]. Six of the 12 mice are the recipients of these freshly harvested bone

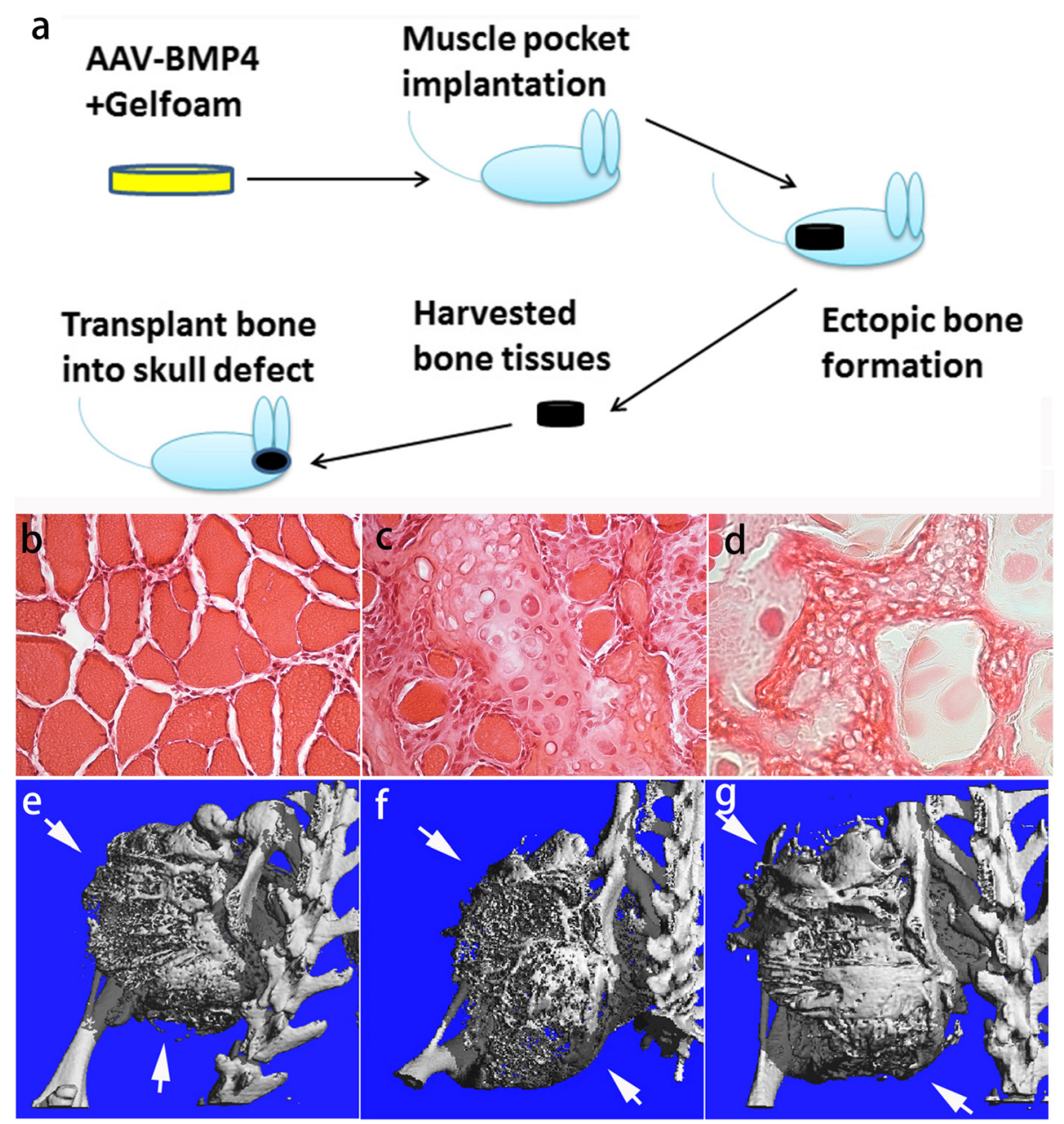

Fig. 1 Two-stage therapeutic utility of ectopically formed bone tissue induced by AAV-BMP4 in skeletal muscle. a Experimental design of two-stage therapeutic utility of ectopically formed bone tissue induced by AAV-BMP4 in skeletal muscle. b-d H\&E staining of sample sections showing that the process of endochondral bone formation was triggered by the AAV-BMP4 with Gelfoam implantation in the muscle pocket. Cartilage (c) and bone (d) tissues were observed at weeks 2 and 4 after the implantation, respectively. e- $\mathbf{g} \mu \mathrm{CT}$ assessments showed ectopic bone tissues appeared at weeks $2(\mathbf{e}), 12(\mathbf{f})$, and $24(\mathbf{g})$ after implantation. The density of ectopic bone tissues increased with time 
grafts and were used as the experimental group, and the other 6 mice have no treatment and were used as the control group. Harvested bone tissue was shaped and resized to fit a 6-mm-diameter skull defect and then transplanted into six host mice (Fig. 1a). The incision was sutured closed, and mice were housed as normal.

\section{Micro-CT exams}

After AAV-BMP4 implantation, mice were checked by micro-computed tomography $(\mu \mathrm{CT})$ at weeks 2,12 , and 24 after surgery. The mice with skull defects were also checked by $\mu \mathrm{CT}$ at weeks 4,12 , and 24 after bone graft transplantation surgery.

\section{Von Kossa/eosin staining}

Frozen sections were fixed in $10 \%$ formalin for $10 \mathrm{~min}$ and were rinsed in distilled water three times. The slides were stained in $2 \%$ silver nitrate solution in the dark for $15 \mathrm{~min}$, rinsed three times in distilled water, and exposed to light for 15-30 min until appropriate stain development. These sections were counterstained with eosin according to the protocol [12].

\section{Results}

Bone tissues were generated in the hind limb skeletal muscle pocket with AAV-BMP4 Gelfoam implantation in vivo

Implantation of Gelfoam containing $15 \mu \mathrm{l}$ of AAV-BMP4 $\left(5 \times 10^{12} \mathrm{vp} / \mathrm{ml}\right)$ in the muscle pocket induced a large amount of ectopic bone tissue histologically (Fig. 1d) and was confirmed by $\mu \mathrm{CT}$ at 2 weeks post implantation (Fig. 1e).

\section{Ectopic bone formation by implantation of AAV-BMP4 Gelfoam underwent endochondral process}

Implantation of AAV-BMP4 with Gelfoam yielded a large amount of bone tissue in the skeletal muscle by both histologically and $\mu \mathrm{CT}$ measurement. The process of bone formation is through endochondral bone formation. Normal histological structure of skeletal muscle is observed prior to AAV-BMP4 with Gelfoam implantation (Fig. 1b). Noticeable cartilage tissue is observed in the tissue section at week 2 after AAV-BMP4 with Gelfoam implantation (Fig. 1c), and bone tissue has formed by week 4 (Fig. 1d). $\mu \mathrm{CT}$ assessment demonstrated ectopic bone tissue formation at weeks 2,12 , and 24 after implantation. The bone density increased with time (Fig. 1e-g).

\section{Transplanted bone graft successfully repaired the skull defect of the host mouse}

The transplanted bone tissues successfully repaired the skull defect by $\mu \mathrm{CT}$ examinations at various time points after surgery. The bone graft gradually modified its dimension with time (Fig. 2a). There is no overgrowth of transplanted bone tissues at the site of the skull defect (Fig. 2b). Under $\mu$-CT and histological examinations, the bony edge of the graft fused with the host bony skull defect effectively in time (Fig. 2c, d).

\section{Discussions}

Skeletal muscle is reported as the easiest infected organ for AAV when compared to other organs in several in vivo studies $[11,13]$. In the present study AAV-BMP4 works very effectively to transform a large amount of skeletal muscles into similar amount of bone tissues in vivo. The histological observations also proved that the process underwent the endochondral bone formation.

Ideally, the new bone regeneration strategy should be simple, cost effective, and as minimally invasive as possible to lessen donor-site morbidity [13-15]. In the present study, the thought of two-stage bone grafting was tested (Fig. 2a). The results demonstrated that ectopic bone tissue has good efficiency and practicality for bone grafting. As thought, the method was superior for the following reasons when compared to the traditional stem cell-based gene therapy. This method omitted a huge amount of in vitro work which included the isolation of stem cells, culturing, passage, virus transduction, and final implantation [16-18]. The bone tissues generated in the muscle pocket are easily harvested and applied in the skull defect. Our results also demonstrated that harvested bone tissues repaired the skull defect without the overgrowth of bone tissues, which is a major side complication of conventional stem cell-based BMP4 gene therapy [5].

The concept of the present study was to help clinicians deal with patients with fracture non-union, bone defects, and spinal fusion. This method will enable one or several "unnecessary" pieces of skeletal muscle of patients to be transformed into the bone tissues needed for bone grafting in vivo. By saying the "unnecessary", it means that transforming the piece of skeletal muscle into bone tissue does not affect normal body function severely. The transformed pieces of skeletal muscles could be the least used muscles or some muscles which did not affect the normal human body function after being removed, such as human palmaris longus muscle and plantaris muscle.

As we know, there are around 650 skeletal muscles in the human body and they make up around half of the total human body weight. Skeletal muscle might become a potential bony autograft bank for patients with a need for bone grafting if the concept of the present study succeeds in future human clinical trial. Future work will investigate how to control the size and orientation of ectopic bone tissue in vivo in its first stage, as well as its 

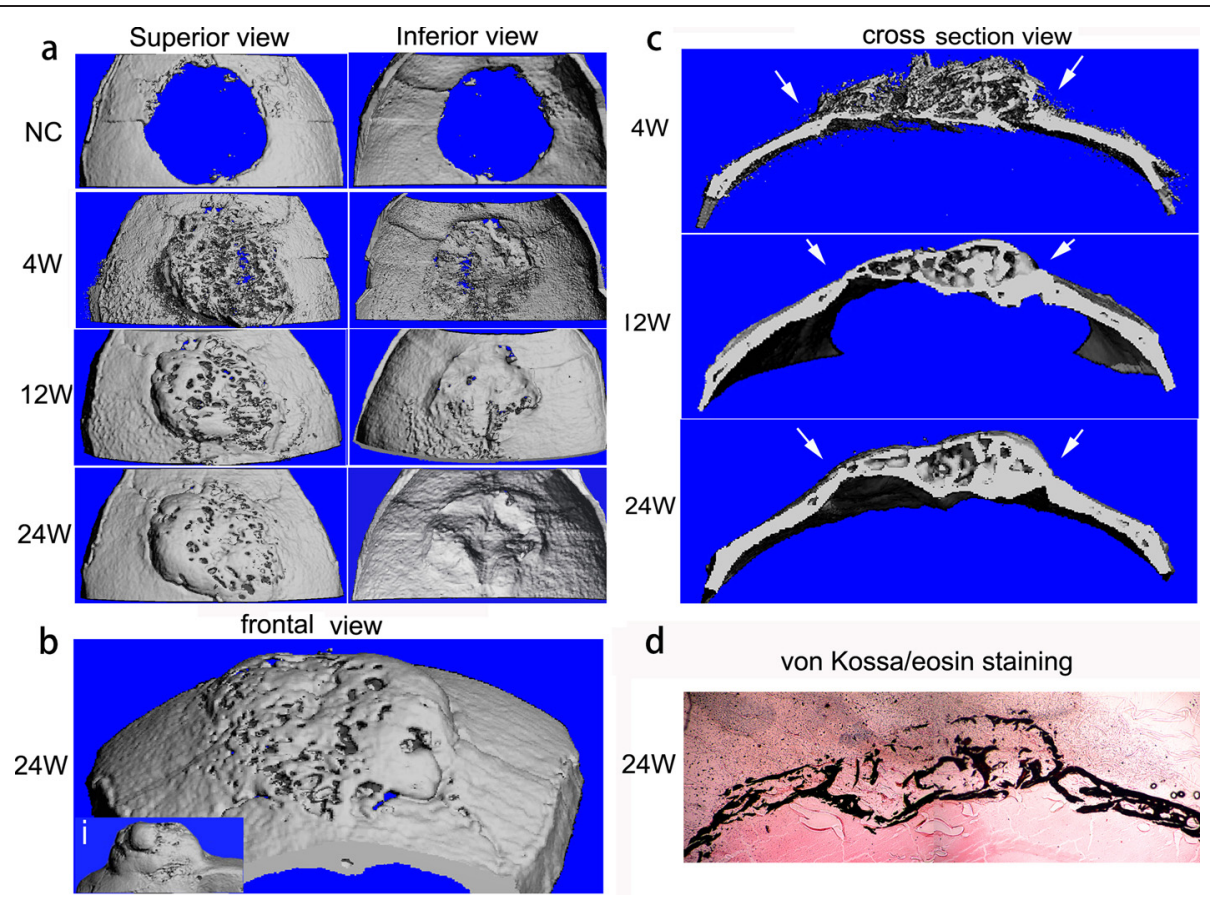

Fig. 2 Ectopic bone tissues repaired skull defect successfully. a $\mu \mathrm{CT}$ assessment showed harvested ectopic bone tissues repaired skull bone defect effectively with time. NC stands for negative control which has no graft implantation. $\mathbf{b}$ At week 24 after transplantation, $\mu C T$ assessments showed there was no bony overgrowth of transplanted ectopic bone graft for skull defect when compared to the MDSC-based gene therapy (bi). c Transplanted bone graft fused well with the host bone edge of skull defect with time. $\mathbf{d}$ Histological results demonstrated that harvested bone graft fused with the host bone tissue efficiently at week 24 post transplantation by von Kossa/eosin staining of sample section

efficiency for the treatment of long-bone defects instead of skull defect.

\section{Conclusion}

Ectopically formed bone tissues triggered by AAV-BMP4 in the skeletal muscle can be used as bone graft for repairing the skull defect, which may be a new strategy for treating clinical orthopedic patients with a need for bone grafts.

\section{Abbreviations}

BMP4: bone morphogenetic protein-4; AAV: adeno-associated virus:

MDSCs: muscle-derived stem cells; SCID: severe combined immune-deficient.

\section{Competing interests}

The authors declare that they have no competing interests.

\section{Authors' contributions}

$\mathrm{KT}$ carried out the experimental design, animal experiment, histological assay, imaging test, and manuscript drafting. MQ carried out the experimental design, animal experiment, histological assay, imaging test, and manuscript drafting. LW carried out the animal experiment and manuscript drafting. ZL carried out the histological assay and imaging test. JX carried out the experimental design and histological assay. YL carried out the animal experiment and histological assay. GL carried out the histological assay and imaging test. BW carried out the AAV vector design and construction. JH carried out the experimental design, coordinated, and helped to draft the manuscript. GL carried out the experimental design, animal experiment, histological assay, imaging test and coordinated and helped to draft the manuscript. All authors read and approved the final manuscript.

\section{Acknowledgements}

We would like to thank Arvydas Usas for the technical support. We are also grateful for the editorial assistance from Jennifer Peckham during the manuscript preparation. This work was supported in part by the National Natural Science Foundation of China (No 81472136) to GL and in part by $\mathrm{NIH}$ Grant 1 R01 DE13420-01 to JH.

\section{Author details}

'Department of Orthopedic Surgery, First Affiliated Hospital of Zhengzhou University, Zhengzhou 450003, Henan, China. ${ }^{2}$ Department of Geriatrics, Luoyang Central Hospital Affiliated to Zhengzhou University, Luoyang 471009, Henan, China. ${ }^{3}$ Molecular Therapy Laboratory, Department of Orthopedic Surgery, University of Pittsburgh, Pittsburgh, PA 15219, USA. ${ }^{4}$ Department of Orthopaedic Surgery, Stem Cell Research Center, University of Pittsburgh School of Medicine, 206 Bridgeside Point II, 450 Technology Drive, Pittsburgh, PA 15219, USA.

Received: 20 March 2015 Accepted: 21 May 2015

Published online: 30 May 2015

\section{References}

1. Wright V, Peng H, Usas A, Young B, Gearhart B, Cummins J, et al. BMP4-expressing muscle-derived stem cells differentiate into osteogenic lineage and improve bone healing in immunocompetent mice. Mol Ther. 2002;6(2):169-78. doi:S1525001602906544.

2. Shen HC, Peng H, Usas A, Gearhart B, Cummins J, Fu FH, et al. Ex vivo gene therapy-induced endochondral bone formation: comparison of muscle-derived stem cells and different subpopulations of primary muscle-derived cells. Bone. 2004;34(6):982-92. doi:10.1016/j.bone.2004.01.028. 58756328204000195.

3. Shen HC, Peng H, Usas A, Gearhart B, Fu FH, Huard J. Structural and functional healing of critical-size segmental bone defects by transduced muscle-derived cells expressing BMP4. J Gene Med. 2004;6(9):984-91. doi:10.1002/jgm.588 
4. Hannallah D, Peng H, Young B, Usas A, Gearhart B, Huard J. Retroviral delivery of Noggin inhibits the formation of heterotopic ossification induced by BMP-4, demineralized bone matrix, and trauma in an animal model. J Bone Joint Surg Am. 2004;86-A(1):80-91.

5. Peng H, Usas A, Hannallah D, Olshanski A, Cooper GM, Huard J. Noggin improves bone healing elicited by muscle stem cells expressing inducible BMP4. Mol Ther. 2005;12(2):239-46. doi:10.1016/j.ymthe.2005.02.027.

6. Rose T, Peng H, Usas A, Josten C, Fu FH, Huard J. Ex-vivo gene therapy with BMP-4 for critically sized defects and enhancement of fracture healing in an osteoporotic animal model. Unfallchirurg. 2005;108(1):25-34. doi:10.1007/ s00113-004-0888-6.

7. Ding H, Gao YS, Hu C, Wang Y, Wang CG, Yin JM, et al. HIF-1alpha transgenic bone marrow cells can promote tissue repair in cases of corticosteroid-induced osteonecrosis of the femoral head in rabbits. PLoS One. 2013;8(5), e63628. doi:10.1371/journal.pone.0063628. PONE-D-12-33518.

8. Deng Y, Bi X, Zhou H, You Z, Wang Y, Gu P, et al. Repair of critical-sized bone defects with anti-miR-31-expressing bone marrow stromal stem cells and poly(glycerol sebacate) scaffolds. Eur Cell Mater. 2014;27:13-24. discussion -5 . vol027a02

9. Chen Y, Luk KD, Cheung KM, Xu R, Lin MC, Lu WW, et al. Gene therapy for new bone formation using adeno-associated viral bone morphogenetic protein-2 vectors. Gene Ther. 2003;10(16):1345-53. doi:10.1038/sj.gt.3301999.

10. Luk KD, Chen Y, Cheung KM, Kung HF, Lu WW, Leong JC. Adeno-associated virus-mediated bone morphogenetic protein-4 gene therapy for in vivo bone formation. Biochem Biophys Res Commun. 2003;308(3):636-45. S0006291X03014293.

11. Wang B, Li J, Fu FH, Xiao X. Systemic human minidystrophin gene transfer improves functions and life span of dystrophin and dystrophin/utrophin-deficient mice. J Orthop Res. 2009;27(4):421-6. doi:10.1002/jor.20781.

12. Li G, Peng H, Corsi K, Usas A, Olshanski A, Huard J. Differential effect of BMP4 on NIH/3T3 and C2C12 cells: implications for endochondral bone formation. J Bone Miner Res. 2005;20(9):1611-23. doi:10.1359/JBMR.050513.

13. Lu CH, Chang YH, Lin SY, Li KC, Hu YC. Recent progresses in gene delivery-based bone tissue engineering. Biotechnol Adv. 2013;31(8):1695-706. doi:10.1016/j.biotechadv.2013.08.015.

14. Malik A, Khan W. Stem cell therapy and tissue engineering applications for bone. Curr Stem Cell Res Ther. 2013;8(3):183-4. CSCRT-EPUB-20130107-2.

15. Oryan A, Alidadi S, Moshiri A, Maffulli N. Bone regenerative medicine: classic options, novel strategies, and future directions. J Orthop Surg Res. 2014;9(1):18. doi:10.1186/1749-799X-9-18.

16. Usas A, Ho AM, Cooper GM, Olshanski A, Peng H, Huard J. Bone regeneration mediated by BMP4-expressing muscle-derived stem cells is affected by delivery system. Tissue Eng Part A. 2009;15(2):285-93. doi:10.1089/ten.tea.2008.0130.

17. Yazici C, Takahata M, Reynolds DG, Xie C, Samulski RJ, Samulski J, et al. Self-complementary AAV2.5-BMP2-coated femoral allografts mediated superior bone healing versus live autografts in mice with equivalent biomechanics to unfractured femur. Mol Ther. 2011;19(8):1416-25. doi:10.1038/mt.2010.294.

18. Zhang C, Wang KZ, Qiang H, Tang YL, Li Q, Li M, et al. Angiopoiesis and bone regeneration via co-expression of the hVEGF and hBMP genes from an adeno-associated viral vector in vitro and in vivo. Acta Pharmacol Sin. 2010;31(7):821-30. doi:10.1038/aps.2010.67.

\section{Submit your next manuscript to BioMed Central and take full advantage of:}

- Convenient online submission

- Thorough peer review

- No space constraints or color figure charges

- Immediate publication on acceptance

- Inclusion in PubMed, CAS, Scopus and Google Scholar

- Research which is freely available for redistribution

Submit your manuscript at www.biomedcentral.com/submit 